\title{
Surgical treatment of active infective endocarditis with paravalvular involvement
}

\begin{abstract}
Aortic root infection remains a challenging problem in the surgical treatment of both native and prosthetic valve endocarditis. Between 1980 and 1991, 73 patients with active aortic valve endocarditis and paravalvular infection underwent operation. Indications for operation included congestive heart failure and uncontrolled sepsis. Aortic root abscesses were located in the noncoronary anulus or in the aorticomitral junction in $45 \%$ of cases, followed by the subannular interventricular septum in $23 \%$. Two patients had an aorticoatrial fistula, seven an interventricular septal defect. Total or partial left ventricular-aortic dehiscence was observed in 27 patients. All patients underwent aortic valve replacement, nine with simultaneous mitral valve operations. Two of the latter required patch reconstruction of the destroyed aorticomitral septum with double valve replacement. Reconstruction of the aortic base was possible in 16 patients, whereas in 12 total replacement of the aortic root was necessary. In one patient, supracoronary aortic valve replacement was used. Recently, topical application of antibiotics in fibrin sealant was used in 25 patients. The operative mortality rate was $21 \%$ and correlated to preoperative uncontrolled sepsis and the presence of extensive root destruction. Operation for active endocarditis of the aortic root requires radical, individualized techniques and results in an acceptable operative and long-term risk. The use of an antibiotic fibrin compound appears to be a useful prophylactic tool to prevent postoperative residual endocarditis. (J THORAC CardiovasC Surg 1994;107:171-7)
\end{abstract}

Go Watanabe, MD, Axel Haverich, MD, Rüdiger Speier, MD, Christoph Dresler, MD, and

Hans Georg Borst, MD, Hannover, Germany

I

In patients with active endocarditis of the aortic valve, early valve replacement has been advocated by many authors, and favorable results have been obtained after both native valve endocarditis (NVE) and prosthetic valve endocarditis (PVE). In recent series, operative mortality rates for early valve replacement ranged from $11 \%$ to $28 \% .{ }^{1.3}$ Valve replacement in cases with infection limited to the leaflets of the valve had been associated with a low incidence of persistent infection. However, extension of the infectious process into the anulus, aortic wall, or subannular intracardiac structures presents a more challenging problem. Here, specific surgical techniques

From the Division of Thoracic and Cardiovascular Surgery, Surgical Center, Hannover Medical School, Hannover, Germany.

Received for publication Aug. 4, 1992.

Accepted for publication May 3, 1993.

Address for reprints: Axel Haverich, MD, Department for Cardiovascular Surgery, Christian-Albrechts-Universität, Arnold-Heller-Str. 7, D-2300 Kiel, Germany.

Copyright $\odot 1994$ by Mosby-Year Book, Inc.

$0022-5223 / 94 \$ 1.00+.10 \quad 12 / 1 / 48809$ have to be applied in addition to valve replacement. Restoring the functional and anatomic integrity of the cardiac structures involved remains the major determinant of early and late results of surgical management of active infective endocarditis.

This report summarizes our experience of valve replacement during the past 11 years in patients with active endocarditis and extensive aortic annular destruction. We emphasize the surgical management and, in particular, the efficacy of antibiotic-releasing carriers for local antibiotic treatment in such cases.

\section{Patients and methods}

Between 1980 and February 1991, 166 consecutive patients with active aortic valve endocarditis underwent operation at our institute. Of these, 73 had paravalvular infection and form the basis of this communication. According to the Stanford criteria, ${ }^{4}$ patients were considered to be in the active phase of endocarditis if the following criteria were fulfilled: (1) clinical features of active infection; (2) positive preoperative blood cultures; (3) intraoperative findings of active infection; and (4) proof of infection in the excised material by histologic staining or culture.

There were 60 men and 13 women ranging in age from 17 to 
Table I. Indications for operation

\begin{tabular}{lcc}
\hline \multicolumn{1}{c}{ Indication } & $n$ & $\%$ \\
\hline Congestive heart failure & & \\
NYHA III & 13 & 18 \\
NYHA IV & 48 & 66 \\
NYHA V (shock) & 5 & 6.8 \\
Sepsis & 26 & 33 \\
Emboli & 11 & 15 \\
$\quad$ Cerebral & 10 & 14 \\
$\quad$ Peripheral & 9 & 12 \\
Atrioventricular block III & 2 & 2.7 \\
Pericardial tamponade &
\end{tabular}

Table II. Microorganisms involved

\begin{tabular}{lrr}
\hline Microorganisms & $n$ & $\%$ \\
\hline Staphylococci & 27 & 37 \\
S. Aureus & 12 & \\
S. Epidermidis & 9 & 19 \\
Streptococci & 14 & \\
S. Viridans & 2 & \\
S. Faecalis & 2 & \\
S. Sanguis & 2 & \\
S. Millerviris & 1 & \\
S. Agalatae & 1 & 1.1 \\
Candida albicans & 3 & \\
Pneumococcus & 1 & \\
Enterococcus & 1 & \\
Serratia & 1 & \\
Klebsiella & 1 & \\
Acinetobacter & 1 & \\
Propionibacterium & 1 & \\
& 60 & \\
\hline
\end{tabular}

78 years (mean age $49.1 \pm 15$ years). Forty-five patients had NVE and 28 had PVE. Isolated aortic valve disease was present in 64 cases; aortic and mitral valve infection was seen in 9 cases. All conditions were diagnosed on clinical and bacteriologic findings supported by echocardiography. The predominant indication for operation was congestive heart failure. Thirteen patients were in New York Heart Association (NYHA) class III $(18 \%), 48$ patients were in class IV $(66 \%)$; and 5 patients $(6.8 \%)$ sustained cardiac arrest during hospitalization and were operated on while they were in cardiogenic shock (class V) (Table I). Uncontrolled sepsis, despite treatment with combinations of antibiotics, was the indication for operation in 26 patients $(36 \%)$ ). Twenty-one patients $(29 \%)$ had had one or more systemic emboli before operation ( 11 cerebral, 10 peripheral). In 9 cases $(12 \%)$, complete atrioventricular heart block was present. Two patients required immediate surgical therapy for cardiac tamponade secondary to rupture of a septic aneurysm. Emergency operation was necessary in 34 patients (47\%) because of uncontrollable sepsis, hemodynamic deterioration, or both (Table I).

The causative microorganisms were identified in the blood culture or in the specimen in 50 patients $(68 \%)$. The predominant organisms were staphylococci; streptococci were the second most frequently detected infectious agents (Table II). Three
Table III. Location and extent of paravalvular infection

\begin{tabular}{ccc}
\hline Abscesses & $n$ & $\%$ \\
\hline Anulus or commissure & 18 & 25 \\
Acoronary sinus & 7 & \\
Coronary commissures & 6 & \\
Other locations & 5 & \\
Subannular & 47 & 64 \\
Aorticomitral junction & 26 & \\
Septal & 17 & \\
Sinus of Valsalva & 3 & \\
Other locations & 4 & \\
VSD/congenital VSD & $7 / 1$ & 37 \\
LV-Ao dehiscence & 27 & \\
\hline L $-A o$. Left ventricular-aortic. & &
\end{tabular}

patients had not received antibiotics preoperatively; the remaining had been receiving antibiotics for 2 days to 8 weeks (mean 2.7 weeks).

The location of annular abscesses and type of extraannular destruction are listed in Table III. Abscess cavities were most commonly located in the noncoronary sinus or at the aorticomitral junction (45\%). The subannular interventricular septum was involved in $23 \%$ of cases and the subcommissural region between the right and left coronary sinus in $8 \%$. Two patients had an aorta-right atrial fistula and one an aorta-left atrial fistula after perforation of a sinus of Valsalva. A ventricular septal defect (VSD) had developed in seven patients. Complete or partial left ventricular-to-aortic dehiscence was observed in 27 patients $(37 \%)$.

Operative techniques. Operations were performed with the use of extracorporeal circulation, systemic hypothermia $\left(28^{\circ}\right.$ C), and cold crystalloid potassium cardioplegia. The operative procedures are listed in Table IV. All patients underwent aortic valve replacement. In eight cases simultaneous mitral valve replacement and in one case mitral valve reconstruction with a pericardial patch were also performed. Abscesses were debrided and all grossly infected material was removed. Paravalvular lesions were then treated according to their size and site with the aim of eliminating the anatomic defect.

The following techniques were used: in small abscess cavities, the defect was obliterated by horizontal mattress sutures supported by Teflon pledgets, which were subsequently used to secure the valve prosthesis. ${ }^{5}$ In 16 patients, autologous pericardial patch closure of cavities was required because of the large diameter of the abscess or for closing an aorticoatrial fistula (simple patch closure) ${ }^{6.7}$ In seven of these patients, the patch was used to close the VSD resulting from a septal abscess. In two patients who had extensive aortic root infection and partial left ventricular-aortic dehiscence, reconstruction of the left ventricular outflow tract was accomplished by the use of a semicircumferential pericardial patch with the valve prosthesis attached to the patch.

In cases with total or subtotal left ventricular-aortic dehiscence, the aortic root was reconstructed by insertion of a composite graft (St. Jude Medical, Inc., St. Paul, Minn.; $n=9)^{8}$ or of an ABO blood group-compatible homograft $(n=3),{ }^{9,}{ }^{10}$ In one patient, supracoronary aortic valve replacement and aortocoronary bypass were used.

In two patients, the aorticomitral septum was destroyed with 
Table IV. Type of surgical procedure used

\begin{tabular}{lc}
\hline \multicolumn{1}{c}{ Procedure } & $n$ \\
\hline Aortic valve replacement & 47 \\
Reconstruction of aortic base & 2 \\
Reconstruction of mitral valve & 1 \\
Aortic and mitral valve replacement & 7 \\
replacement of aortomitral junction & 2 \\
Insertion of valved conduit & 9 \\
Insertion of homograft conduit & 3 \\
Insertion of homograft valve & 1 \\
Translocation of aortic valve & 1 \\
Total & $\frac{1}{73}$ \\
Additional procedures & \\
Aortocoronary bypass & 3 \\
RIMA bypass & 1 \\
Tricuspid valve reconstruction & 2 \\
Bigelow procedure & 1 \\
VSD closure & $\frac{8}{15}$ \\
Total &
\end{tabular}

RIMA, Right internal mammary artery.

partial destruction of the leaflets of either valve. One of these patients had an associated VSD. Reconstruction of the fibrous skeleton with a triangular pericardial patch and double valve replacement were done in one patient. In the other patient, the aortotomy was extended into the left atrium, generating a common mitral and aortic valve orifice. After excision of both the entire aorticomitral septum and of both valves, a new septum of autologous pericardium was inserted followed by double valve replacement according to the principles described by David and Feindel ${ }^{11}$ and Borst. ${ }^{12}$

Biologic valves were used in the majority of procedures before 1985 , whereas mechanical valves were exclusively implanted after 1986 except in the three patients who received homografts.

To ensure a high concentration of antibiotics in the infected area and in an attempt to prevent recurrent infection, a mixture of antibiotics and fibrin sealant was used in a total of 25 patients. For this purpose, $10 \mathrm{mg}$ of neomycin sulfate (Nebacetin, Byk Gulden, Konstanz, Germany) and $4 \mathrm{ml}$ of fibrin glue (Tissucol, Immuno GmbH, Heidelberg, Germany) were mixed (ABF glue). After debridement of the infected tissue, $\mathrm{ABF}$ glue was injected into the abscess cavities. Also, the sewing rings of prosthetic valves and the Dacron graft in composite grafts were soaked with ABF glue before implantation. ${ }^{13}$ Characteristics of this subgroup of patients regarding the extent of paravalvular involvement compared with those of the remaining patients are given in Table V. Follow-up was obtained in 53 of 58 survivors by personal communication with the patient or private physician, extended to a maximum of 11 years.

\section{Results}

The overall early ( 30 day) mortality rate was $21 \%$ (Table VI). Eight patients died of uncontrollable septicemia and multiple organ failure, five of pump failure and low output syndrome, and one of cardiac arrhythmia. The early mortality rate for PVE (32\%) was higher than that for NVE (13\%). Also, the early mortality rate was
Table V. Pathologic findings in patients treated with $A B F$ glue compound compared with those treated with conventional operation

\begin{tabular}{cc}
\hline Group & $n$ \\
\hline ABF (+) & 25 \\
Annular involvement & 6 \\
Subannular involvement & 17 \\
LV-Ao dehiscence & 7 \\
ABF (-) & 48 \\
Annular involvement & 12 \\
Subannular involvement & 30 \\
LV-Ao dehiscence & 20
\end{tabular}

More than one feature was present in certain patients. Thus the number of pathologic findings in each group exceeds the number of patients. $A B F(+)$, patients treated with $\mathrm{ABF} ; A B F(-)$, patients treated with conventional operation; $L V-A O$, left ventricular-aortic.

Table VI. Hospital mortality (total and various subgroups)

\begin{tabular}{lcc}
\hline & $n$ & $\%$ \\
\hline Total & $15 / 73$ & 21 \\
NVE & $6 / 45$ & 13 \\
PVE & $9 / 28$ & 32 \\
Preoperative sepsis & & \\
$\quad$ Controlled & $9 / 26$ & 32 \\
$\quad$ Uncontrolled & $6 / 47$ & 13 \\
Preoperative NYHA class & & \\
$\quad$ III & $3 / 20$ & 15 \\
IV & $10 / 48$ & 20 \\
$\quad$ Shock & $3 / 5$ & 60 \\
LV-Ao dehiscence & $11 / 33$ & 33 \\
$\quad$ Intracardiac fistula present & $5 / 40$ & 13 \\
Intracardiac fistula absent &
\end{tabular}

$L V-A o$, Left ventricular-aortic.

significantly higher in patients with preoperative sepsis $(35 \%)$ and in the presence of extensive paravalvular destruction (left ventricular-aortic dehiscence or intracardiac fistula, Fig. 1, Table VI). In patients with preoperative acute circulatory failure (NYHA class IV and V), the mortality rate tended to be higher (five of these patients had preoperative episodes of cardiac arrest).

The most common nonfatal perioperative complication was complete atrioventricular block (17 patients). In eight patients, block occurred only postoperatively and two of these had initially had a VSD. Five patients required intraaortic balloon pump support because of low output syndrome and six required hemodialysis for acute renal failure. In 11 patients, pneumonia developed. Four patients $(5.5 \%)$ had reexploration of the mediastinum for bleeding.

Recurrent endocarditis was seen in eight patients $(11 \%)$ and seven underwent reoperation. Another four 


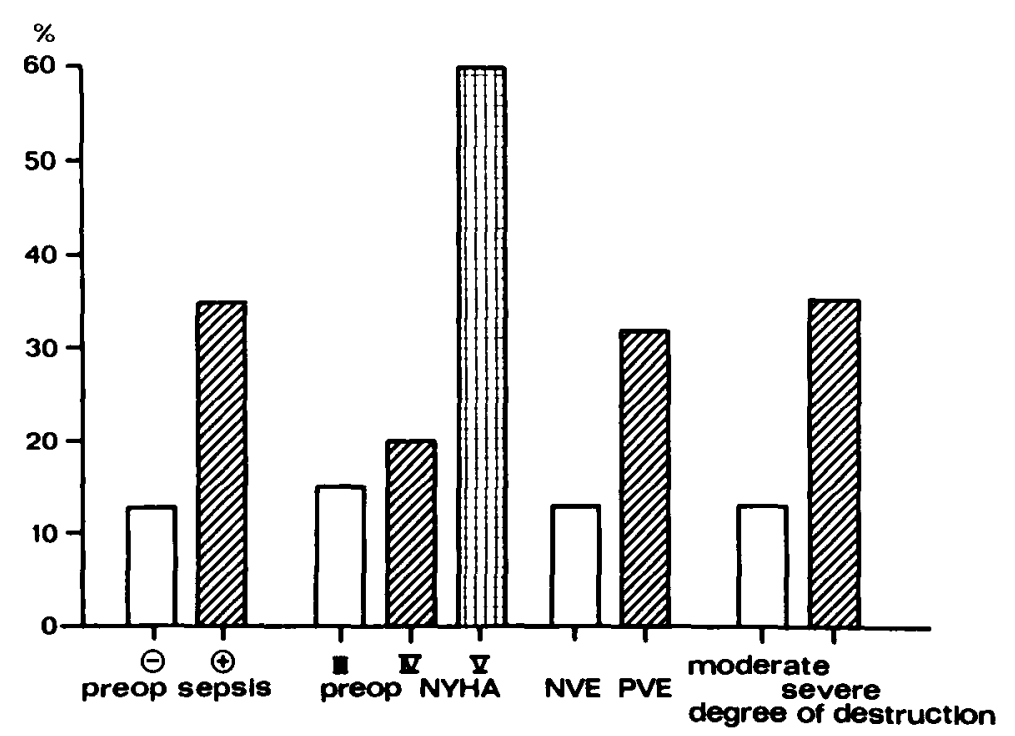

Fig. 1. Early mortality in subgroups of patients with various risk factors.

patients were reoperated on for paravalvular leakage. One ultimately required heart transplantation because of congestive heart failure (long-term survivor at $4 \frac{1}{2}$ years) for a total reoperation rate of $21 \%$ ( $12 / 58$ hospital survivors).

Late deaths occurred in 17 patients $(29 \%)$, for an overall actuarial 10 -year survival of $62 \%$. With the exclusion of early mortality, 10 -year survival was $78 \%$; $86 \%$ in patients with NVE and $62 \%$ for those with PVE (Fig. 2). The major cause of late mortality was recurrent endocarditis (five patients). Of the eight patients with residual or recurrent endocarditis, one patient was electively treated medically and died of congestive heart failure and sepsis. Seven patients underwent a second operation and one of these underwent a third valve replacement: the total early mortality rate for these patients was $57 \%(4 / 7)$. There were four late deaths caused by carcinoma and two as a result of cerebrovascular accidents. In five patients, death occurred at home and the causes remain unknown.

In the ABF group $(n=25)$, two patients $(8 \%)$ died early of cardiogenic shock and cerebral emboli, respectively. There were 13 early deaths $(27 \%)$ in the group in which ABF was not used $(p<0.05)$. Serious infectionrelated complications including residual PVE and postoperative sepsis occurred in one patient (4\%) in the ABF group and in 12 of the non-ABF patients $(25 \%)(p<0.05$; Table VII). Actuarial survival at 1,3 , and 5 years was significantly higher in the ABF group $(p<0.05 ;$ Fig. 3$)$.

\section{Discussion}

Early operation for active bacterial endocarditis not responding to antibiotic therapy is now a widely accepted strategy in the treatment of such patients. The outcome of patients with the infectious process limited to the valve leaflets treated surgically has improved during the past 10 years. ${ }^{14-16}$ Paravalvular aortic root infection, however, still results in a significantly increased mortality and in frequent recurrence of infection, especially in the presence of large annular abscesses or left ventricular-aortic dehiscence. In recent reports on the surgical treatment of infective endocarditis, the incidence of annular abscess formation was found to be increased when compared with that in previous series. ${ }^{15-17}$

The pathomechanism of paravalvular infection in endocarditis is thought to be multifactorial. In cases with NVE, the process may initially involve the valve leaflets alone. Ongoing infection will then lead to its extension into anulus and adjacent structures with abscess formation or left ventricular-aortic dehiscence. In addition, aortic-to-atrial fistula or a VSD may occur. In patients with PVE, infection of the prosthesis originates at the sewing ring and then extends to the periprosthetic tissue. ${ }^{18}$ The extension and degree of paraannular destruction appears to correlate with the virulence of the infective organism and the duration of the infection. Many authors have indicated that endocarditis caused by staphylococci represents a particularly virulent process and is associated with a rapidly deteriorating hemodynamic state. ${ }^{6,10,19-22}$ Also, development of conduction disturbances and annular abscess formation are observed more commonly with this type of infection. ${ }^{15,19}$

In our series, staphylococci were the most common organisms. This is in contrast to the spectrum of infectious organisms in our total series of bacterial endocarditis 


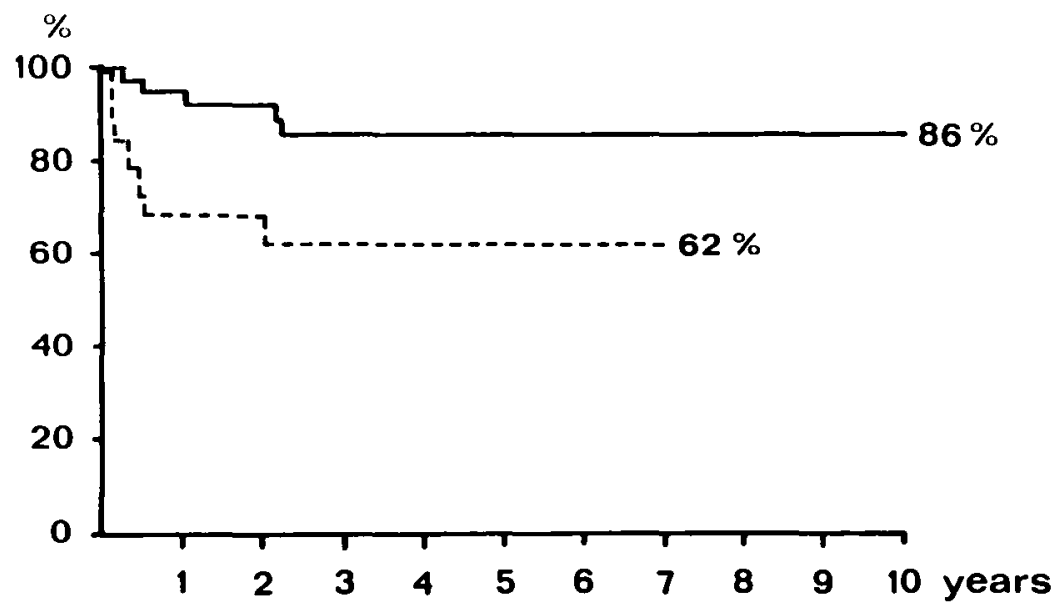

Fig. 2. Actuarial survival of patients with NVE (solid line) and PVE (dotted line) up to 10 years. Early mortality (see Fig. 1) has been excluded.

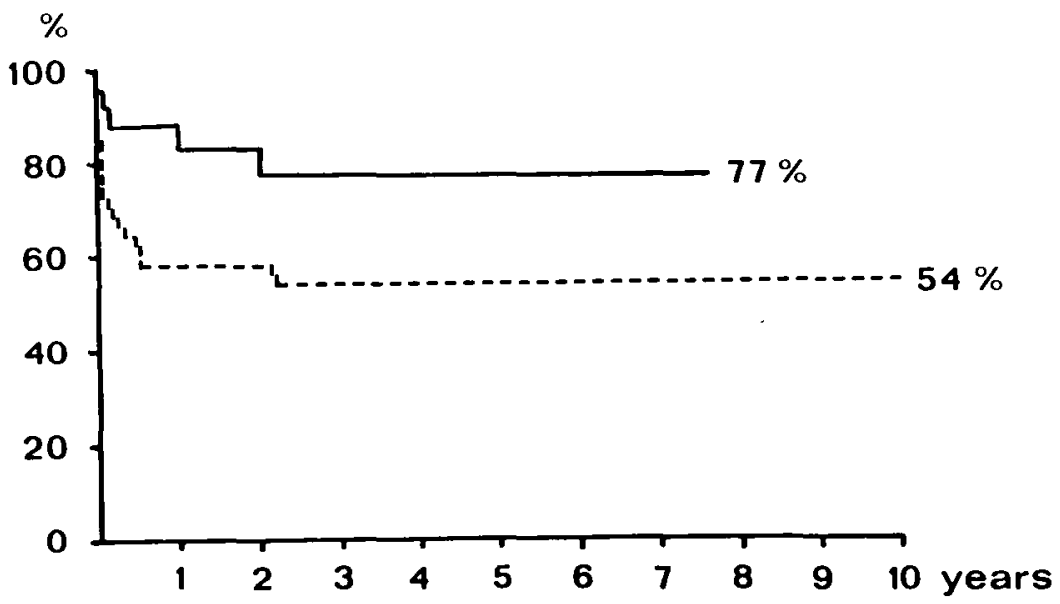

Fig. 3. Actuarial survival of patients treated with ABF glue compound (solid line) compared with non-ABF patients (dotted line); $p<0.05$ at 1,3 , and 5 years).

including those without paravalvular involvement. Here, infections with staphylococcus accounted for only $21 \%$, comparable with figures recorded by other groups. It can therefore be concluded that an endocarditis caused by staphylococcus may more often result in paravalvular destruction than in endocarditis caused by other bacteria. Early operation may thus be advocated in all cases in which staphylococci are grown. Similarly, early operation seems to be warranted in cases with PVE, inasmuch as the most severe destruction of paraannular tissue (including left ventricular-aortic dehiscence) was seen in this subgroup. These findings would support previous studies on surgical treatment of prosthetic valve endocarditis. $9,20,23-25$

Among common clinical features of active endocardi-
Table VII. Efficacy of the application of the $A B F$ glue compound

\begin{tabular}{lccc}
\hline Outcome & ABF & Controls & $\mathrm{p} \mathrm{Value}$ \\
\hline $\begin{array}{l}\text { Early mortality } \\
\text { Residual or recurrent } \\
\text { endocarditis }\end{array}$ & $2 / 25$ & $13 / 48$ & $<0.05$ \\
$\begin{array}{l}\text { Infection-related death } \\
\text { NS, Not significant. }\end{array}$ & 1 & 11 & $\mathrm{NS}$ \\
& & & $<0.05$ \\
\hline
\end{tabular}

tis such as persistent fever unresponsive to antibiotics and aortic insufficiency of recent onset, only the de novo diagnosis of complete atrioventricular block may be diagnostic of aortic anulus destruction. ${ }^{10,18}$ In our series, nine patients showed complete atrioventricular block preoper- 
atively. The principal indication for surgical therapy was rapid or progressive hemodynamic deterioration secondary to valvular and paravalvular destruction. ${ }^{5,10,26}$ Very often, though, operation may come too late if the indication is guided by symptoms of cardiac failure, inasmuch as the operative mortality has been shown to correlate with the degree of congestive heart failure. ${ }^{10,20,24}$ In this context, the operative mortality rate of $21 \%$ observed in our patients appears acceptable in view of the large number of patients with advanced congestive heart failure. Sixty-six percent of patients in the present series were in NYHA class IV, and five were in shock before operation. In $47 \%$ of the patients, valve replacement was performed as an emergency.

The principles of surgical treatment of active endocarditis with paravalvular destruction are (1) to debride infected tissue to eradicate the infectious focus, (2) to exclude abscess cavities from the circulation, (3) to restore ventricular-aortic continuity without tension, (4) to provide a safe anchorage to the valve prosthesis, and (5) to prevent local recurrence of infection. Several effective surgical techniques have been described for the treatment of paravalvular destruction. Debridement and obliteration of the abscess is usually successful if the cavities are small. ${ }^{4}$ With larger abscesses, a patch of Dacron fabric ${ }^{5}$ or autologous pericardium ${ }^{6}$ can be sewn into viable surrounding tissue. To repair more severe forms of annular defects resulting in extensive left ventricular-aortic dehiscence, other and more aggressive techniques have to be used. Early in our series we performed supracoronary aortic valve replacement combined with aortocoronary bypass grafting (translocation method). ${ }^{8,26}$ With this technique, however, cavities are not excluded from the circulation and long-term survival will depend on the durability of the venous grafts. In other cases, the dehiscence was obliterated with the use of Teflon-reinforced horizontal mattress sutures that were subsequently used to secure the valve prosthesis. ${ }^{5,6}$ In these patients, however, a high rate of residual endocarditis was encountered. More recently, aortic root reconstruction with a semicircumferential pericardial patch has been preferred. ${ }^{7,27}$

In cases with subtotal or complete left ventricularaortic dehiscence, we prefer aortic root replacement with a valved composite Dacron graft ${ }^{28}$ or a homograft. ${ }^{9}, 29$ The incidence of recurrent endocarditis after aortic root replacement with valved composite grafts and homograft conduits was low (8.3\%) and early mortality tended to be lower than after application of traditional procedures. The only disadvantage of this technique may be an increased incidence of postoperative complete atrioventricular block, which was observed in 4 of 12 patients.

The potential advantage of using cryopreserved homograft conduits as compared with mechanical valves or valved composite grafts seems to rest in a lower risk of reinfection. ${ }^{30}$ Also, safely anchoring the graft may be easier because of the pliable nature of the material. ${ }^{31}$ There is, however, the distinct disadvantage of a limited availability of homografts, which may be especially important in patients requiring urgent or emergency operation.

The local application of a mixture of ABF glue may reduce the risk of residual or recurrent infection. This method was adapted from experimental studies in which pretreatment of prosthetic valve rings with the $A B F$ compound resulted in binding of sufficient amounts of antibiotics for at least 2 weeks and the Dacron rings remained sterile in culture after direct contamination with Staphylococcus aureus solution. ${ }^{13}$

Currently, $15 \%$ to $21 \%$ of patients undergoing prosthetic valve replacement for active bacterial endocarditis will have postoperative sepsis or recurrent endocarditis. ${ }^{17,19,21}$ A similar incidence (25\%) was found in our subset of patients in which no antibiotics were applied topically. In the group in which the glue compound was used, the incidence of residual endocarditis and postoperative infection-related complications was reduced to $4 \%$. Unfortunately, patients were not assigned randomly to the two treatment groups.

Except for one, all surgeons in our institution adopted this technique during the past 5 years. On the basis of the results presented herein, the application of $A B F$ compound has now become routine at our clinic. Even considering the drawbacks of a retrospective analysis, our data would nevertheless indicate that this procedure may serve as a prophylactic tool against perioperative reinfection.

We conclude from this study that the indication for operation in patients with active bacterial endocarditis with paravalvular destruction must be guided by clinical, hemodynamic, echocardiographic, and bacteriologic findings. In general, operation should be performed earlier than it was in most of the patients presented herein, especially if staphylococcus can be identified as the causative organism. The same holds true for cases of PVE, in which perivalvular destruction is usually advanced and particularly resistant to conservative therapy.

Paying attention to basic surgical principles such as extensive debridement followed by tension-free reconstruction of the left ventricular outflow tract, operation may be done with an acceptable operative risk and longterm results. In cases of left ventricular-aortic dehiscence, replacement of the aortic root with valved composite grafts or homograft conduits offers a number of advantages in reducing the risk of reinfection or paravalvular 
leakage. In addition, the use of the $\mathrm{ABF}$ glue compound appears to be an efficient prophylactic tool to prevent postoperative residual endocarditis and serious infectionrelated complications.

\section{REFERENCES}

1. Aslamaci S, Dimitri WR, Williams BT. Operative considerations in active native valve infective endocarditis. $\mathrm{J}$ Cardiovasc Surg 1989;30:328-33.

2. Arbulu A, Asfaw I. Management of infective endocarditis: seven year's experience. Ann Thorac Surg 1987;43:144-9.

3. Lewis BS, Agathangelou NE, Colsen PR, et al. Cardiac operation during active infective endocarditis. J THORAC CARDIOVASC SURG 1982;84:579-84.

4. Stinson EB. Surgical treatment of infective endocarditis. Prog Cardiovasc Dis 1979;22:145-52.

5. Shumacker HB. Aneurysms of the aortic sinuses of Valsalva due to bacterial endocarditis, with special reference to their operative management. J ThORAC CardovasC SURG 1972;63:896-902.

6. Symbas PN, Vlasis SE, Zacharopoulos L, Lutz JF. Acute endocarditis: surgical treatment of aortic regurgitation and aortico-left ventricular discontinuity. J THORAC CARDIOvaSC SURG 1982;84:291-6.

7. Fiore AC, Ivey TD, McKeown PP, Misbach GA, Allen MD, Dillard DH. Patch closure of aortic annulus mycotic aneurysms. Ann Thorac Surg 1986;42:372-9.

8. Turina M. Prosthetic valve endocarditis. Thorac Cardiovasc Surg 1982;30:350-3.

9. Lau JK, Robles A, Cherian A, et al. Surgical treatment of prosthetic endocarditis. J THORAC CARdiovasc Surg 1984; 87:712-6.

10. Kirklin JK, Kirklin JW, Pacifico AD. Aortic valve endocarditis with aortic root abscess cavity: surgical treatment with aortic valve homograft. Ann Thorac Surg 1988; 45:674-7.

11. David TE, Feindel CM. Reconstruction of the mitral anulus. Circulation 1987;76(Suppl):III102-7.

12. Borst HG. Repair of septic aortic root defects without conduit. J Cardiac Surg 1990;5:44-7.

13. Karck M, Siclari F, Wahlig H, et al. Pretreatment of prosthetic valve sewing-ring with the antibiotic/fibrin sealant compound as a prophylactic tool against prosthetic valve endocarditis. Eur J Cardiothorac Surg 1990;4:142-6.

14. Willcox BR, Murray GF, Starek PJK. The long-term outlook for valve replacement in active endocarditis. J THORAC Cardiovasc Surg 1977;74:860-3.

15. D'Agostino RS, Miller DC, Stinson EB, et al. Valve replacement in patients with native valve endocarditis: what really determines operative outcome. Ann Thorac Surg 1985;40:429-38.
16. Robinson MJ, Reudy J.Sequelae of bacterial endocarditis. Am J Med 1962;32:922-8.

17. Ergin MA, Raissi S, Follis F, et al. Annular destruction in acute bacterial endocarditis. J THORAC CARDIOVASC SURG 1989;97:755-63.

18. Arnett EN, Roberts WC. Valve ring abscess in active infective endocarditis: Frequency, location and clues to clinical diagnosis from the study of 95 necropsy patients. Circulation 1976;54:140-5.

19. Richardson JV, Karp RB, Kirklin JW, Dismukes WE. Treatment of infective endocarditis: a 10-year comparative analysis. Circulation 1978;58:589-97.

20. Borst HG, Hetzer R, Deyerling W. Surgery for active infective endocarditis. Thorac Cardiovasc Surg 1982; 30:345-9.

21. Baumgartner WA, Miller CD, Reitz BA, et al. Surgical treatment of prosthetic valve endocarditis. Ann Thorac Surg 1983;35:87-104.

22. David TE, Komeda M, Brofman PR. Surgical treatment of aortic root abscess. Circulation 1989;80(suppl I):269-74.

23. Sande MA, Scheld WM. Combination antibiotic therapy of bacterial endocarditis. Ann Intern Med 1980;92:390-5.

24. Cukingnan RA, Carey JS, Wittig JH, et al. Early valve replacement in active infective endocarditis. J THORAC Cardiovasc Surg 1983;85:163-73.

25. VanHooser DW, Johnson RG, Hein RA, et al. Successful management of aortic valve endocarditis with associated periannular abscess and aneurysm. Ann Thorac Surg 1986;42:148-50.

26. Danielson GK, Titus JL, DuShane JW. Successful treatment of aortic valve endocarditis and aortic root abscesses by insertion of prosthetic valve in ascending aorta and placement of bypass graft to coronary arteries. J THORAC Cardiovasc Surg 1974;67:443-9.

27. David TE, Bos J, Christakis GT, et al. Heart valve operations in patients with active infective endocarditis. Ann Thorac Surg 1990;49:701-5.

28. Frantz PT, Murray GF, Wilcox BR. Surgical management of left ventricular discontinuity complicating bacterial endocarditis. Ann Thorac Surg 1987;29:1-7.

29. Kirklin JK, Kirklin W, Pacifico AD. Aortic valve endocarditis with aortic root abscess cavity: surgical treatment with aortic valve homograft. Ann Thorac Surg 1988; 45:674-7.

30. Kirklin JW, Barratt-Boyes BG. Aortic valve disease. In: Kirklin JW, Barratt-Boyes BG, eds. Cardiac surgery. New York: John Wiley, 1986:373-429.

31. Tuna IC, Thomas AO, Schaff HV, et al. Results of homograft aortic valve replacement for active endocarditis. Ann Thorac Surg 1990;49:619-24. 